\title{
SEX, SOCIO-ECONOMIC STATUS AND SELF EFFICACY ON LEVELS OF HOPE OF ADOLESCENTS IN NIGERIA
}

\author{
Imhonde, Odhianosen Henry. PhD ${ }^{1}$ \\ ${ }^{\text {I}}$ Professor, Department of Psychology, Ambrose Alli University, Ekpoma, Edo State, Nigeria. \\ Idiakheua, Edison Omogenfe. $\mathrm{PhD}^{2}$ \\ ${ }^{2}$ Senior Lecturer, Department of Psychology, Ambrose Alli University, Ekpoma, Edo State, Nigeria. \\ Ohakwe, Chinagozim Gift. PhD ${ }^{3}$ \\ ${ }^{3}$ Lecturer 1, Institute of Theology, Paul University, Awka, Nigeria.
}

DOI: https://doi.org/10.36713/epra3809

\begin{abstract}
This study investigated the influence of parental socio-economic status, and perceived self-efficacy on hope in adolescents. This study became necessary as adolescents are living in a frustrating world, deprived of traditional social support, an unstable economy characterised by galloping inflation and massive unemployment.130 students in higher institution and graduates within the ages 19 -30 years participated in the study by completing the author developed 15 item hope and self-efficacy scale, which measured their hope in education, law enforcement agencies, politics, economy, security, health and the nation in general. Pooled data treated with the Student t-test of the matched sample revealed that adolescents differ in their hope. Males reported higher hope than females. And both reported less hope in the institutions in the country and a high hope in themselves, and as such belief in what they can do to escape the felt poverty. The study made recommendations based on the context of the study.

KEYWORDS: Hope, adolescents, nation induced poverty, frustration, lack of hope, and ongoing distress
\end{abstract}

\section{INTRODUCTION}

Snyder, Irving \& Anderson (1991, as cited in Snyder, (2000) defined hope as "a positive motivational state that is based on an interactively derived sense of successful (a) agency (goal-directed energy) and (b) pathways (planning to meet goals)". Watching young children on a playground reveals a need to know about hope. A child's vision transforms a series of obstacles (tall ladders, hard to reach monkey bars, wobbly wooden bridges) into limitless opportunities for fun. Goals become very clear ("I am going to swing across all the monkey bars"), the plan develops ("I am going to climb the ladder, grab the bar, and swing from the first one to the second one"), and support is requested
(“Can you help me up?") while confidence grows ("I think I got it. Yeah, I am doing it!").

Hope has long been recognized as an important component of psychological growth and changes. Freud (1905/1968) believed that many of the benefits of psychoanalysis could be explained by patients' "expectations, coloured by hope and faith" in the treatment process. Later, Menninger (1959) urged mental health practitioners to study hope, "a basic but elusive ingredient in our daily work". It was described as an anchor of survival. Like Freud, Menninger suggested that many psychotherapeutic gains might be attributable to increased hope during treatment. Subsequent theorists have extended his assertion, giving hope a central role in therapy. For example, Frank (1971) described patients as demoralized individuals who lacked hope. $\mathrm{He}$ argued that the

| Volume: 4 | Issue: 11 | November| 2019 Journal DOI: https://doi.org/10.36713/epra2016 |www.eprajournals.com |182 | 
"arousal of the patient's hope" was common to all psychological treatments, and necessary to alleviate suffering. Similarly, Yalom (1995) described the installation of hope as crucial to any therapy--an essential component necessary for clients to initiate and sustain their involvement in the therapeutic process over time.

As the flowers of tomorrow are in the seeds of today, so are the adults of tomorrow in the children of today. In the children of today, one sees the hope for the continuity of society. Some years ago, today adults were children, what has caused the whole difference is time. With time, children become adult, while adults mature and undergo self-liberation. So there is a strong need to understand the role of socio-economic status and self-efficacy on hope among adolescents in Nigeria.

Psychologists along with other educational colleagues (teachers, counsellors, social workers, administrators) are more than passive observers of the hope of children and youth. In fact, "caring coaches" (Snyder, 1994) in schools contribute greatly to helping students and schools become hopeful places for children. This study is interested in exploring the hope that is alive in the adolescents who is developing in a nation induced poverty, high crime rate, galloping inflation, high cost of living, removal of fuel subsidy, gross unemployment of the educated, in a nation blessed with abundant natural resources on the playground and the soccer field, and in the classroom and in the music hall.

Accumulating evidence suggests that hope is related to life satisfaction and well-being. Some researchers (e.g., Gilman, Dooley, \& Florell, 2006) suggests that hope scores are correlated negatively and significantly with measures of internalizing and externalizing behaviour problems, indicators of psychological distress and school maladjustment. In terms of direct relationships with positive outcomes, in a sample of 367 Portuguese middle-school students, Marques, Pais-Ribeiro, and Lopez (2007c) found that hope is significantly and positively correlated with global life satisfaction and mental health.

Research suggests that hope may play a role in student health. Berg, Rapoff, Snyder, and Belmont (2007) investigated the relationship between hope and adherence to a daily-inhaled steroid regimen among 48 asthma patients ages 8 to 12 . Students with low hope experience high anxiety, especially in competitive, testtaking situations. The underlying presumption of this anxiety is that such students often do not use feedback from failure experiences in an adaptive manner to improve their future performances (Onwuegbuzie \& Snyder, 2000).

That hope is advantageous for people of all ages in several important areas, including showing up. Hopeful students are more likely to go to school, and hopeful employees are far more involved and enthusiastic at work. Sustained effort willpower (the agency component of hope) translates to sustained effort on academic and work tasks, and it is associated with more compliance in healthcare situations. Productive Hopeful workers are more likely to be engaged, satisfied, and creative.

Longevity and health hopeful people live longer and live better. In health, hopeful people consistently tolerate more pain than their less hopeful counterparts, and they are more likely to eat vegetables and fruits, exercise regularly, quit smoking, and practice safe sex. Hope leads to satisfaction with life and positive emotions and seems to be quite closely connected to meaning in life and purpose in life, as well as to social savvy and support.

Nevertheless, defining hope provides little information about its development. To date, it is clear that hope is built on a foundation of contingency thinking (Snyder, 1994) and that it is socially primed (Snyder, Cheavens, \& Sympson, 1997). There are likely two major factors affecting the hope of adolescents contextual (family and peers) and personal (personality and sex). Recent research (Marques, PaisRibeiro, \& Lopez, 2007b) supports previous thinking about how caregivers foster hope development in children (Snyder, 1994).

High-hope individuals - as compared to lowhope individuals - are more likely to develop alternative pathways, especially when the goals are important and when obstacles appear (Snyder, Sympson, et al., 1996). However, pathways are useless without the associated agency-inducing cognitions (Snyder, Cheavens, \& Michael, 1999; Snyder, Michael, \& Cheavens, 1999). These agency thoughts are reflected in the positive self-talk that is exhibited by high-hope individuals (e.g., "I can do this" or "I will not give up"; Snyder, LaPointe, Crowson, \& Early, 1998). High-hope people are sustained by their agency thinking when confronted with challenging situations or impediments (Snyder, 1994, 1999). Thus, high-hope more than low-hope people exhort themselves to "take the next step" or to take a long-range goal and separate it into steps (i.e., "stepping”).

Co-relational findings indicate that a child's higher hopeful thinking is positively associated with perceived competence and self-esteem or self-worth (Marques, Pais-Ribeiro, \& Lopez, 2007c), and negatively associated with symptoms of depression (Snyder, Hoza, et al., 1997). Indeed, researchers have reported that lower hope predicts more depressive symptoms (Kwon, 2000), and it does so independently of other coping strategies (Chang \& DeSimone, 2001). Additional evidence suggests that children and adolescents (Snyder, Hoza et al., 1997), as well as young adults (Snyder, Harris, et al., 1991) who report higher levels of hope also view themselves in a favourable light and have slight positive self-referential illusions.

Regarding views about the future, those with high hope typically are more optimistic, they focus on success rather than failure when pursuing goals (Snyder, Hoza, et al., 1997), they develop many life goals, and they perceive themselves as being capable of solving problems that may arise (Snyder, Hoza, et al., 
1997). Likewise, recent research suggests that higher hope is linked closely to having a greater perceived purpose in life (Feldman \& Snyder, 2005).

That is, rather than using such feedback constructively, low-hope individuals are prone to selfdoubt and negative ruminations that interfere with attending to the appropriate cues for both inputting (i.e., studying) and outputting information (i.e., testtaking; Michael, 2000; Snyder, 1999). High-hope students, on the other hand, do not derogate their abilities when they "fail," and they do not let such failures affect their self-worth over time. In this regard, the high-hope students make adaptive attributions that the "failure" feedback merely means that they did not try hard enough in a given instance, or that they did not identify the correct studying or test-taking strategies.

Higher hope has been positively related to superior athletic (and academic performances) among student-athletes (Curry, Maniar, Sondag, \& Sandstedt, 1999). When hopeful thinking is stymied, interpersonal struggles may result. For instance, ruminations block adaptive goal-related thinking and cause increased frustration and aggression against others (Collins \& Bell, 1997; Snyder \& Feldman, 2000). Hope is positively associated with perceived competence and self-worth (Marques, Pais-Ribeiro, \& Lopez, 2009) and negatively associated with symptoms of depression (Snyder, Hoza, et al., 1997).

High-hope students typically are more optimistic (Snyder, Hoza, et al., 1997), develop many life goals, and perceive themselves as being capable of solving problems that may arise (Snyder, Hoza, et al., 1997). Accumulating evidence suggests that hope is related to life satisfaction and well-being (e.g., Gilman, Dooley, \& Florell, 2006). Hope plays a role in student health in areas such as adherence to treatment among asthma children patients (Berg, Rapoff, Snyder, \& Belmont, 2007). Hope is linked consistently to attendance and credits earned (Gallup, 2009a). Hopeful middle school students have better grades in core subjects (Marques, Pais-Ribeiro, \& Lopez, 2011) and on achievement tests (Snyder, Hoza, et al., 1997). Hopeful high school students (Gallup, 2009b; Snyder et al., 1991) and beginning college students (Gallagher \& Lopez, 2008; Snyder et al., 2002) have higher overall grade point averages.

Hope predicts academic achievement, and the predictive power of hope remains significant even when controlling for intelligence (e.g., Snyder, Cheavens, \& Sympson, 1997), prior grades (e.g., Gallagher \& Lopez, 2008; Snyder et al., 1991; Snyder et al., 2002), self-esteem (Snyder et al., 2002), personality (Day, Hanson, Maltby, Proctor, \& Wood, 2010), and college entrance examination scores such as high school GPA and ACT/SAT (Gallagher \& Lopez, 2008; Snyder et al., 2002). Higher hope has been positively related to superior athletic (and academic) performances among student-athletes (e.g., Curry, Maniar, Sondag, \& Sandstedt, 1999), even after statistically controlling for variance related to their natural athletic abilities.
Higher hope has been correlated positively with social competence (Barnum, Snyder, Rapoff, Mani, \& Thompson, 1998), pleasure in getting to know others, enjoyment in frequent interpersonal interactions (Snyder, Hoza, et al., 1997), and interest in the goal pursuits of others (Snyder, Cheavens, \& Sympson, 1997). Besides, the interpersonal problems of others can translate into lowered hope for children. On this point, children who have witnessed family members or friends who have been victims of interpersonal violence have shown lower levels of hope than children who have not seen such violence (Hinton-Nelson, Roberts, \& Snyder, 1996).

Hope can exist as a relatively stable personality disposition (i.e., a trait), or as a more temporary frame of mind (i.e., a state). Similarly, hopeful thought can occur at various levels of abstraction. For example, one can be hopeful about achieving: (a) goals in general (i.e., a trait); (b) goals in a certain life domain (e.g., school); or (c) one goal in particular. Lopez, Ciarlelli, Coffman, Stone, and Wyatt (2000) provide in-depth coverage of these latter approaches, including the development and validation of various self-report, observational, and narrative measures of hope.

High hope in developed countries such as America may be easier to achieve than in third world countries. On the other hand it may be that hope levels remain the same no matter what situation an individual is in, rather the goals you aim for differ, (for example an individual in the U.S.A may have the goal of going to university while an individual in the third world may have the goal of providing food for their family). There is a strong need to understand a measure of hope among Nigerians adolescents.

The World Health Organization (WHO) defines adolescence as young people in the ages of 10-19 years old. There are about 1.3 billion adolescents, a fifth of the world population and their numbers are increasing. Adolescence is the developmental period between childhood and adulthood between the period of 12-22 years. It is a transitional period in the human life span linking childhood and adulthood, adolescence is said to have discontinuity with childhood and continuity with adulthood, and a period of rapid development characterized by increase biological, social and cognitive changes. Biological, social and cognitive processes are inextricably intertwined to bring about the ongoing changes in growth and development.

Adolescence is an exciting and tumultuous time, it is the period of gender intensification, parental control separation, opportunity for social affiliation, and preparation for life career, it is also a period when they prepare for West Africa Examination Council and Joint Admission and Matriculation Board which determines their fate as to what they can read, the adolescents wrestles with separation, pushes more rapidly for independence from parents, and becomes keenly interested in other adults as role models. The adolescents' primary allegiance shifts from parents to peers, as peers groups ideals and values take new importance, forming a second family. Peers help 
validate the adolescent push for separation at home, and in negotiating this shift, the adolescent commonly battles with authority figures.

In the struggle between the wish to satisfy new sexual urges and the wish to control them, adolescents often vacillate between hedonism and asceticism. Their capacity for self-observation and insight increases greatly and the adolescent begins to think about who he or she is.

\section{Hope Theory}

Snyder and colleagues (Snyder, 1989, 1994, 2000a, 2000b; Snyder, Harris, et al., 1991) characterized hope as a human strength manifested in capacities to (a) clearly conceptualize goals (goals thinking), (b) develop the specific strategies to reach those goals (pathways thinking), and (c) initiate and sustain the motivation for using those strategies (agency thinking). Goals-thinking is ubiquitous in youth, but often untamed and unrefined. Pathways and agency thinking are both necessary, but neither by itself is sufficient to sustain successful goal pursuit. As such, pathways and agency thoughts are additive, reciprocal, and positively related, but they are not synonymous.

Whereas other positive psychology constructs such as goal theory (Covington, 2000; Dweck, 1999), optimism (Scheier \& Carver, 1985, Boman, Russo, Furlong, Lilles, \& Jones, 2008 ), self efficacy (Bandura, 1982), and problem-solving (Heppner \& Petersen, 1982) give differentially weighted emphases to the goal itself or to the future-oriented agency- or pathways-related processes, hope theory equally emphasizes all of these goal-pursuit components (Snyder, 1994).

Comparisons of the similarities and differences between hope theory and other theories (e.g., achievement motivation, flow, goal setting, mindfulness, optimism, optimistic explanatory style, problem-solving, resiliency, self-efficacy, self-esteem, and Type A behaviour pattern), see Magaletta and Oliver (1999), Peterson (2000), Snyder, (1994), and Snyder, Rand, and Sigmon (2002).

From the above, this study, therefore, hypothesises that adolescents will report a negative score on hope scale, and that of the report, there will be a sex difference in their report and Adolescents who report high social economic status will report high score on hope scale compared to Adolescents from low social economic status.

\section{METHOD}

\section{Participants}

One hundred and twenty students selected from Esan Central Senatorial District in Edo State with an age range of 17-19 participated in the study.

\section{Instrument}

The instrument used in obtaining data from the participants was a 15 item questionnaire designed to measure hope, its item was selected from existing hope scale, due to differences in culture and context, the items were chosen to meet with the culture of the research context. The response format was in four option of $1=$ not at all, $2=$ slight hope, $3=$ moderate hope and $4=$ very high hope. The scale was designed to measure hope in six areas of life namely family, legal institution, academic institution, law enforcement, work-life, and the nation in general.

\section{Procedure}

The instrument was given to the selected participants individually aided by the school teachers, they were told that participation is voluntary and no punishment is attached to non-participation, but they should be honest in their response. Completed questionnaires were collected the same day after the exercise. Pooled data were treated using the multiple regression analysis to predict their hope in the six areas of life.

\section{RESULT.}

Pooled data treated revealed that adolescents have high hope in certain areas of life than others as shown in the table below.

Table 1. Showing the result obtained from the response by male and females to institutions in various sphere of life.

\begin{tabular}{lrrrrrrl}
\multicolumn{1}{c}{ N } & M & SD & t & df & p & \\
\hline Males & 70 & 10.52 & 2.24 & 2.54 & 118 & $<0.05$ \\
Females 50 & 5.57 & 4.05 & & & \\
\hline High SES 60 & 7.36 & 3.32 & 3.03 & 118 & $<0.05$ \\
Low SES 60 & 11.08 & 1.98 & & & \\
\hline
\end{tabular}

\section{DISCUSSION}

This study reveals that males reported a high level of hope than females, this finding supports the divine instructions that men are to have dominion over the earth, subdue it and provide for the females, so they can build their hope in men. This study also reported that there are different levels of hope among adolescent, it was observed that the older the individual the lesser the hope, this may result from the real changes that affect the cognition as children who are fed, being protected they may not know how well their parents are doing to keep food on table, but as they approach the end of school or when they have left school to enrol in other schools they begin to feel better, and develop lesser hope in the nation and its institute.

This study find support with the findings of who classified hope as high and low (Snyder, Sympson, et al., 1996) and asserted that high-hope individuals as compared to low-hope individuals are more likely to develop alternative pathways, especially when the goals are important and when obstacles appear ( Snyder, Sympson, et al., 1996). However, pathways are useless without the associated agency-inducing cognitions (Snyder, Cheavens, \& Michael, 1999; Snyder, Michael, \& Cheavens, 1999). These agency thoughts are reflected in the positive self-talk that is exhibited by high-hope individuals (e.g., "I can do this" or "I will not give up"; Snyder, LaPointe, Crowson, \& Early, 1998). High-hope people are sustained by their agency thinking when confronted with challenging

| Volume: 4 | Issue: 11 | November| 2019 Journal DOI: https://doi.org/10.36713/epra2016|www.eprajournals.com |185 | 
situations or impediments (Snyder, 1994, 1999). Thus, high-hope more than low-hope people exhort themselves to "take the next step" or to take a longrange goal and separate it into steps (i.e., "stepping"): (a) Increased hopefulness, (b) Improved life satisfaction, and (c) decreased psychological distress among participants.

The above finding of this study is not surprising as adolescence is very likely to manifest this behaviour. A cursory look reveals that many of the adolescence would have suffered some degree of frustration, resulting from deprivation by examination bodies

\section{RECOMMENDATIONS}

For example, Snyder, Lopez, and Pedrotti (2011) describe "hope therapy" a series of interventions designed to elicit hopeful cognitions and reduce distress among adults referred to individual, marital, and group counselling. Similarly, Magyar-Moe (2010) views hope as "a malleable strength that can serve as an important therapeutic change agent". She describes several hope enhancement strategies and suggests that mental health practitioners use these techniques in their practice. Cheavens and colleagues offer specific ways therapists might increase hopeful thoughts in their clients within the context of cognitive therapy (Cheavens, Feldman et al., 2006) and describe how clinicians might use various hope enhancement strategies to treat patients with Major Depressive Disorder (Cheavens \& Gum, 2010). Others suggest using hope enhancement techniques with children. For example, Nel (2010) describes how clinicians might use narrative approaches to instil hope in clinic-referred youths. Snyder, McDermott, and colleagues, (1997), describe how similar hope enhancement strategies can be used for the treatment of AttentionDeficit/Hyperactivity Disorder, Major Depressive Disorder, and Oppositional Defiant Disorder in children. Furthermore, Lopez and colleagues (2009) describe how these strategies might be implemented in public schools "for enhancing hope in all children" ( $p$. 42). Hope enhancement strategies have also been suggested in related disciplines, such as counselling (Larsen \& Stege, 2010), marriage and family therapy (Ripley \& Worthington, 2002), health psychology (Hollis, Massey, \& Jevne, 2007), and nursing (Herth, 2001; Turner \& Stokes, 2006).

This study considering the context of study of the study therefore suggest, positive family social environments, especially, cohesive and warm relationships with appropriate expressed emotions among family members this is essential in the development of hope, as hope is a multidimensional dynamic life force characterized by a confident yet uncertain expectation of achieving a future good. For hope to be achieved it must be realistic, possible, and personally significant.

That psychologists and education professionals should use and refine techniques for enhancing hope in children, who become adolescence. Adolescence is known to involve changes in the self-concept, social relationship, cognitive development and social experience. The foundation of imparting hope rests on helping students set goals. The goals, of course, must be calibrated to the student's age and specific circumstances. Among many adolescents, who often need encouragement to set goals in various life domains, sometimes these goals relate to interpersonal matters such as wanting to feel happier or meeting new people, whereas at other times they may involve selecting a career or deciding whether to go to college. By helping adolescents to select several goals, they can turn to their other important goals when they face a profound blockage in one goal.

Assuming students have been helped to establish desired goals, the next step is to teach them how to set clear markers for such goals. These markers enable the students to track progress toward the goals. A common goal, but one in our view that is quite counter-productive, is the vague "getting good grades." This and similar goals are sufficiently lacking in clarity that the student cannot know when they are attained (Pennebaker, 1989). Moreover, related research shows that abstract goals are more difficult to reach than wellspecified goals (Emmons, 1992).

Thus, we advocate concrete markers such as, "to study an hour each day in preparation for my next biology exam." With this latter goal, students not only can tell when they have reached it, but they also can experience a sense of success. Furthermore, the followings are recommended:

* Encourage goals that excite students.

* Calibrate goals to the student's age and specific circumstances.

* Discuss and encourage goals in various life domains and help students to rank them by importance.

* Help students select several goals. They can turn to their other important goals when they face a profound blockage in one goal.

* Teach students how to set clear markers for goals (e.g., instead of "getting good grades," support concrete markers such as, "to study an hour each day in preparation for my next math exam").

* Encourage them to establish approach goals (more productive).

* Support students to think in terms of "we" goals in addition to their own "me" goals.

* Help students develop pathways thinking. Strategies for helping students develop pathways thinking include the following

* Help students to break down large goals into smaller sub-goals (step-by-step sequence).

* Encourage students to think about their goals (e.g., what will you need to do to attain your goal?) and to identify several routes to the desired goal (e.g., what would you do if you encounter a blockage?).

* Support "keep-going thinking." If one pathway does not work, try other routes.

* Help students learn not to attribute a blockage to a perceived lack of talent. Instead, help the 
student to search productively for another route that may work.

* Help students to recognize if they need a new skill and encourage them to learn it.

* Remind them that they can always ask for help.

* Help students enhance their agency thinking. Strategies for helping students develop agency thinking include the following.

* Keep in mind that goals that are built on internal, personal standards are more energizing than those based on external standards (e.g., imposed by peers, parents, or teachers).

* Help students to set "stretch" goals based on their previous performances.

* Help students to monitor their self-talk (e.g., via a notebook or audio tape recorder) and encourage them and talk in positive voices (e.g., I can do this; I will keep at it).

* Engage children in exciting activities that involve teamwork.

* Tell students stories and provide them with books that portray how other students have succeeded or overcome adversity.

* Encourage students to enjoy and to learn through the process of getting to their goals.

\section{CONCLUSION}

This study is an exploratory study to understand the hope status of a sample of Nigerians, mostly as adolescents are growing up in a country characterised by lack of structures to accommodate the teeming population commonly in education, as a lot of interested adolescents in a field of study cannot be offered admission despite a relatively high score in their JAMB, PUME. The goal of this study was to understand the differential level of hope in adolescents in a country with a high cost of living and hope is daunted. It was found that adolescence has a high degree of hope in their person. Hope is a highly personal concept, a therapeutic energy tool that can have a powerful effect on an individual's motivation towards personal well-being.

\section{REFERENCES}

1. Bandura, A. (1982). Self-efficacy mechanism in human agency. American Psychologist, 37, 122-147.

2. Berg, C. J., Rapoff, M. A., Snyder, C. R., छे Belmont, J. M. (2007). The relationship between children's hope for pediatric asthma treatment adherence. Journal of Positive Psychology, 2, 176-184.

3. Boman, P., Russo, R., Furlong, M. J., Lilles, E., छ Jones, C. (2009). Optimism and the school context. In R. Gilman, E. S. Huebner, \& M. J. Furlong (Eds.), The handbook of positive psychology in the schools (pp. 51-64). New York: Routledge

4. Chang, E. C., \& DeSimone, S. L. (2001). The influence of hope on appraisals, coping, and dysphoria: A test of hope theory. Journal of Social and Clinical Psychology, 20, 117-129.

5. Covington, M. V. (2000). Goal theory, motivation, and school achievement: An integrative review. Annual Review of Psychology, 51, 171-200.
6. Curry, L. A., Maniar, S. D., Sondag, K. A., छ Sandstedt, S. (1999). An optimal performance academic course for university students and student-athletes. Unpublished manuscript. University of Montana, Missoula.

7. Dweck, C. S. (1999). Self-theories: Their role in motivation, personality, and development. Philadelphia: Psychology Press.

8. Emmons, R. A. (1992). Abstract versus concrete goals: Personal striving level, physical illness, and psychological well-being. Journal of Personality and Social Psychology, 62, 292-300.

9. Feldman, D. B., \& Snyder, C. R. (2005). Hope and the meaningful life: Theoretical and empirical associations between goal-directed thinking and life meaning. Journal of Social \& Clinical Psychology, 24, 401-421.

10. Gilman, R., Dooley, J., \& Florell, D. (2006). Relative levels of hope and their relationship with academic and psychological indicators among adolescents. Journal of Social and Clinical Psychology, 25, 166-178.

11. Heppner, P. P., \& Petersen, C. H. (1982). The development and implications of a personal problemsolving inventory. Journal of Counseling Psychology, $29,66-75$.

12. Hinton-Nelson, M. D., Roberts, M. C., छ Snyder, C. R. (1996). Early adolescents exposed to violence: Hope and vulnerability to victimization. American Journal of Orthopsychiatry, 66, 346-353.

13. Kwon, P. (2000). Hope and dysphoria: The moderating role of defence mechanisms. Journal of Personality, 68, 199-223.

14. Lopez, S. J., Ciarlelli, R., Coff man, L., Stone, M., छे Wyatt, L. (2000). Diagnosing for strengths: On measuring hope building blocks. In C. R. Snyder (Ed.), Handbook of hope: Theory, measures, and interventions (pp. 57-85). San Diego, CA: Academic Press.

15. Marques, S. C., Pais-Ribeiro, J. L., \& Lopez, S. J. (2007a). Validation of a Portuguese version of the Children Hope Scale. Submitted for publication.

16. Marques, S. C., Pais-Ribeiro, J. L., छ Lopez, S. J. (2007b, July). Relationship between children's hope and the guardian's hope. Poster presented at the Xth European Congress of Psychology, Prague, Czech Republic.

17. Marques, S. C., Pais-Ribeiro, J. L., E Lopez, S. J. (2007c, July). Hope in relation to life satisfaction, mental health, and self-worth in students. Poster presented at the Xth European Congress of Psychology, Prague, Czech Republic.

18. Marques, S. C., Pais-Ribeiro, J. L., \& Lopez, S. J. (2007d, October). Role of hope, satisfaction with life and self-worth in academic achievement and mental health. Poster presented at the Sixth International Positive Psychological Summit, Washington DC.

19. Michael, S. T. (2000). Hope conquers fear: Overcoming anxiety and panic attacks. In C. R. Snyder (Ed.), Handbook of hope:Theory,measures, and applications (pp. 355-378). San Diego, CA: Academic Press.

20. Onwuegbuzie, A. J., EO Snyder, C. R. (2000). Relations between hope and graduate students' studying and testtaking strategies. Psychological Reports, 86, 803806.

21. Pennebaker, J. W. (1989). Stream of consciousness and stress: Levels of thinking. In J. S. Uleman $\S^{\circ} J . A$. Bargh (Eds.), Unintended thought (pp. 327-349). New York: Guilford.

22. Peterson, C. (2000). The future of optimism. American Psychologist, 55, 44-55. 
23. Scheier, M. F., E Carver, C. S. (1985). Optimism, coping, and health: Assessment and implications of generalized outcome expectancies. Health Psychology, 4, 219-247.

24. Snyder, C. R. (1994). The psychology of hope: You can get there from here. New Tork: Free Press.

25. Snyder, C. R. (1999). Hope, goal blocking thoughts, and test-related anxieties. Psychological Reports, 84, 206208.

26. Snyder, C. R. (Ed.). (2000a). Handbook of hope:Theory,measures, and applications. San Diego, CA: Academic Press.

27. Snyder, C. R. (2000b). The past and possible futures of hope. Journal of Social and Clinical Psychology, 19, $11-28$.

28. Snyder, C. R. (2002). Hope theory: Rainbows in the mind. Psychological Inquiry, 13, 249-275.

29. Snyder, C. R.; Berg, C., Woodward, J.T., Gum, A., Rand, K.L., Wrobleski, K.K., Brown, J., \&ं Hackman, A. (2005). Hope against the cold: Individual differences in trait hope and acute pain tolerance on the cold pressor task. Journal of Personality, 73, 287-312.

30. Snyder, C. R., Cheavens, J., \& Michael, S. T. (1999). Hoping. In C. R. Snyder (Ed.), Coping: The psychology of what works (pp. 205-231). New York: Oxford University Press.

31. Snyder, C. R., Cheavens, J., \& Sympson, S. C. (1997). Hope: An individual motive for social commerce. Group Dynamics: Theory, Research, and Practice, 1, 107-118.

32. Snyder, C. R., E Feldman, D. B. (2000). Hope for the many: An empowering social agenda. In C. R. Snyder
(Ed.), Handbook of hope: Theory, measures, and applications (pp. 402-415). San Diego, CA: Academic Press.

33. Snyder, C. R., Rand, K. L., \& Sigmon, D. R. (2002). Hope theory: A member of the positive psychology family. In C. R.Snyder \& S. Lopez (Eds.), Handbook of positive psychology (pp. 257-266) New York: Oxford University Press.

34. Snyder, C. R., Hoza, B., Pelham, W. E., Rapoff, M., Ware, L., Danovsky, M., Highberger, L., Ribinstein, H., E Stahl, K. J. (1997). The development and validation of the Children's Hope Scale. Journal of Pediatric Psychology, 22, 399-421.

35. Snyder, C.R., Irving, L., \& Anderson, J.R. (1991). Hope and Health: Measuring the will and the ways. In C.R. Snyder \& D.R. Forsyth (Eds.) Handbook of social and clinical psychology: The health perspective (pp.285305). Elmsford, New York: Pergamon Press. Cited in Snyder, C.R. (2000). Hypothesis: There is Hope. In C.R. Snyder (Eds.), Handbook of Hope Theory, Measures and Applications (pp.3-21).

36. San Diego: Academic Press. Snyder, C. R., Harris, C., Anderson, J. R., Holleran, S. A., Irving, L. M., Sigmon, S. T., Oshinoubu, L., Gibb, J., Langelle, C., छे Harney, P. (1991). The will and the ways: Development and validation of an individual differences measure of hope. Journal of Personality and Social Psychology, 60, 570-585. 